\title{
Apnea Testing: The Effects of Insufflation Catheter Size and Flow on Pressure and Volume in a Test Lung
}

\author{
Nicholas R Henry MSc RRT-NPS AE-C and S Gregory Marshall PhD RRT RPSGT RST
}

\begin{abstract}
BACKGROUND: The apnea test is used to determine the absence of respiratory drive when determining brain death. Current guidelines for performing the apnea test do not specify the size of insufflation catheter (IC) to use with each endotracheal tube (ETT) size, despite case reports describing procedure-related complications with the use of various IC sizes. We studied the effect of the ratio of IC outer diameter to ETT inner diameter on the pressure and volume generated within the lungs during the apnea test. METHODS: We tested ETTs with inner diameters of 6.0-10.0 mm, IC outer diameters of 10-16 French, and oxygen-supply tubing, at oxygen flows of 6-15 L/min, in an intubation manikin connected to a test lung. RESULTS: The multivariate analysis of variance method identified significant differences in the pressures and volumes during the apnea test $(P<.001)$, and the Tukey method identified significant differences in the pressures and volumes associated with IC/ETT ratios $\geq 0.7$ and $<0.7(P<.05)$. CONCLUSIONS: An IC with an outer diameter $<70 \%$ of the ETT inner diameter, at $6 \mathrm{~L} / \mathrm{min}$, may prevent inappropriate lung pressure and volume during the apnea test. This recommendation, coupled with current American Academy of Neurology guidelines for the determination of brain death, may reduce the risk of procedure-related complications. Key words: $\mathrm{CO}_{2}$ challenge; apnea test; brain death. [Respir Care 2014;59(3):406-410. (C) 2014 Daedalus Enterprises]
\end{abstract}

\section{Introduction}

The most accepted guideline for the determination of brain death, from the American Academy of Neurology, describes the necessary assessment elements, which include a clinical evaluation (neurological assessment) and a $\mathrm{CO}_{2}$ challenge or another ancillary test. ${ }^{1-3}$ The $\mathrm{CO}_{2}$ challenge, also known as the apnea test, is an essential component in determining brain death, because it establishes the absence of a neurological stimulus for respiratory drive. ${ }^{1}$

The authors are affiliated with the Department of Respiratory Care, Texas State University, San Marcos, Texas.

The authors have disclosed no conflicts of interest.

Mr Henry presented a version of this paper at the Open Forum of the 58th AARC Congress, held November 10-13, 2012, in New Orleans, Louisiana.

Correspondence: Nicholas R Henry MSc RRT-NPS AE-C, Department of Respiratory Care, Texas State University, 601 University Drive, San Marcos, TX 78666. E-mail: NH14@txstate.edu.

DOI: $10.4187 /$ respcare.02499
According to the American Academy of Neurology guideline, the procedure for the apnea test involves disconnecting the patient from the ventilator for approximately 8 min while maintaining oxygenation by advancing an insufflation catheter (IC) into the endotracheal tube (ETT), to the level of the carina. ${ }^{1}$ The IC delivers $100 \%$ oxygen at $6 \mathrm{~L} / \mathrm{min}^{1,2}$ However, the guideline does not specify the size of IC to use during the apnea test. ${ }^{1,2}$

Complications of the apnea test include hypoxia, hypotension, cardiac arrhythmias, cardiac arrest, excessive hypercarbia, and pneumothorax..$^{2,4-8}$ Interestingly, while the occurrence of pneumothoraces during the apnea test is believed to be rare, ${ }^{9}$ several case reports have described pneumothoraces within minutes of initiating the apnea test. $3,7-8,10$ The case reports describe various oxygen flows, IC sizes, and the use of nasal-cannula tubing or oxygensupply tubing for the IC. . $^{37-8,10}$ Similar clinical accounts led us to the following research question. What pressures and volumes are generated in the lungs during the apnea test with various IC sizes and various oxygen flows? The objective of this study was to identify the appropriate IC and ETT sizes to minimize the pressure and volume in the lungs during the apnea test. Our null hypothesis was that 
there would be no statistically significant difference in the peak pressures or volumes in a test lung with various IC outer diameter to ETT inner diameter (IC/ETT) ratios, with the American Academy of Neurology recommended oxygen flow of $6 \mathrm{~L} / \mathrm{min}$.

\section{Methods}

This study was approved by our institutional review board. We used an anatomically correct intubatable manikin (RespiTrainer Advance, IngMar Medical, Pittsburgh, Pennsylvania), and a test lung (QuickLung, IngMar Medical, Pittsburgh, Pennsylvania). The volume measurement by the manikin is a calculated from the lung pressure with the formula:

\section{(peak pressure - minimum pressure)/compliance}

The test lung was set to a normal compliance setting, $50 \mathrm{~mL} / \mathrm{cm} \mathrm{H}_{2} \mathrm{O}$, and a resistance of $5 \mathrm{~cm} \mathrm{H}_{2} \mathrm{O} / \mathrm{L} / \mathrm{s}$. Prior to data collection we calibrated the pressure transducer per the manufacturer's recommendations.

The manikin was intubated with cuffed ETTs (SunMed, Largo, Florida) with inner diameters of $6.0-10.0 \mathrm{~mm}$. The tip of each ETT was advanced to exactly $2 \mathrm{~cm}$ above the carina, and the ETT cuff was inflated. We tested IC sizes of 10-16 French (Burak Healthcare, Costa Mesa, California). We also tested an IC made from oxygen-supply tubing (Hudson RCI, Research Triangle Park, North Carolina) with an outer diameter of $6.0 \mathrm{~mm}$ (18 French), measured with a digital caliper (Kobalt, North Wilkesboro, North Carolina).

Each IC was advanced through the ETT and positioned precisely to the end of the ETT by matching the length markings on the IC to the length markings on the ETT. Because the oxygen-supply tubing did not have length markings, we made a length marking on the tubing for consistency to ensure that it did not pass the end of the ETT.

For each IC and the oxygen-supply tubing, 100\% oxygen was delivered via a back-pressure-compensated Thorpe-tube-type flow meter (Precision Medical, Northhampton, Pennsylvania). Standard 7-foot oxygen supply tubing (Hudson RCI/Teleflex Medical, Research Triangle Park, North Carolina) connected the flow meter to the IC. To reduce parallax error, the oxygen flow was measured by aligning the middle of the Thorpe tube flow meter float at eye level with the correct flow marking on the Thorpe tube flow meter. The delivered oxygen flow was adjusted through the range $6-15 \mathrm{~L} / \mathrm{min}$ in $1-\mathrm{L} / \mathrm{min}$ increments. The flow measurements were validated with a thermal mass flow meter (TSI, Shoreview, Minnesota). We delivered the oxygen flow until the test lung pressure and volume reached

\section{QUICK LOOK}

\section{Current knowledge}

The apnea test determines the presence/absence of respiratory drive when assessing for brain death. The apnea test guidelines do not specify the size of insufflation catheter to use, relative to the endotracheal tube size.

\section{What this paper contributes to our knowledge}

An insufflation catheter with an outer diameter $<70 \%$ of the endotracheal tube's inner diameter, and a flow of $6 \mathrm{~L} / \mathrm{min}$, decrease the risk of inappropriately high lung pressure and volume during the apnea test.

a sustained plateau, and recorded that pressure and volume.

The IC/ETT ratio for each IC and ETT combination was calculated by dividing the IC outer diameter by the ETT inner diameter. The IC/ETT ratios were considered in 6 groups: $<0.5,0.5-0.54,0.55-0.59,0.6-0.64,0.65-0.69$, and $\geq 0.7$. The use of the ratio of IC to ETT size for selecting the proper IC size is well documented as the common means for comparing IC size to ETT size. ${ }^{11-13}$ Table 1 displays the calculated IC/ETT ratios we tested.

We used the multivariate analysis of variance method and the Tukey honest significant difference test to assess the pressures and volumes. An alpha of .05 was considered statistically significant.

\section{Results}

Table 2 shows the mean peak pressures, and Figure 1 shows the mean peak pressures at $6 \mathrm{~L} / \mathrm{min}$. Multivariate analysis of variance identified statistically significant differences between the pressures and volumes with the 6 IC/ETT ratios $(P<.001)$. The Tukey honest significant difference test indicated that pressure with an IC/ETT of $\geq 0.7$ were significantly greater than the pressures with the IC/ETT ratios $<0.7$ (all $P<.05$ ).

Table 3 show displays the mean volumes, and Figure 2 shows the mean peak volumes at $6 \mathrm{~L} / \mathrm{min}$. The Tukey honest significant difference test indicated that the volume with an IC/ETT of $\geq 0.7$ was significantly greater than the volume associated with the IC/ETT ratios $<0.7$ (all $P<.05)$.

\section{Discussion}

The 1995 Report of the Quality Standards Subcommittee of the American Academy of Neurology states, "place 
Apnea Testing: The Effects of Insufflation Catheter Size and Flow

Table 1. Ratios of the Inner Diameter of the Endotracheal Tube to the Outer Diameter of the Insufflation Catheter

\begin{tabular}{cccccc}
\hline \hline $\begin{array}{c}\text { ETT Inner } \\
\text { Diameter } \\
(\mathrm{mm})\end{array}$ & \multicolumn{5}{c}{ Insufflation Catheter Size, French } \\
\cline { 2 - 6 } & 10 & 12 & 14 & 16 & 18 \\
\hline 6.0 & 0.55 & 0.67 & 0.78 & 0.89 & 1.00 \\
6.5 & 0.51 & 0.62 & 0.72 & 0.82 & 0.92 \\
7.0 & 0.48 & 0.57 & 0.67 & 0.76 & 0.86 \\
7.5 & 0.44 & 0.53 & 0.62 & 0.71 & 0.80 \\
8.0 & 0.42 & 0.50 & 0.58 & 0.67 & 0.75 \\
8.5 & 0.39 & 0.47 & 0.55 & 0.63 & 0.71 \\
9.0 & 0.37 & 0.44 & 0.52 & 0.59 & 0.67 \\
9.5 & 0.35 & 0.42 & 0.49 & 0.56 & 0.63 \\
10.0 & 0.33 & 0.40 & 0.47 & 0.43 & 0.60 \\
\hline
\end{tabular}

a cannula at the level of the carina."2 The word "cannula" is ambiguous in this context and may have led some clinicians to mistakenly use nasal cannula tubing to administer the oxygen during the apnea test.7,8 Although the subsequent 2010 Report of the Quality Standards Subcommittee of the American Academy of Neurology revised the wording to "place an insufflation catheter through the endotracheal tube,"1 the guideline does not indicate the IC size, even though the IC size affects the risk of pneumothoraces. ${ }^{3,9}$

We included oxygen tubing because it is common practice in the apnea test in many locations. The use of oxygen tubing or nasal cannula tubing poses several concerns. First, oxygen tubing and nasal cannula tubing do not have length markings, so the clinician could advance the tubing past the end of the ETT and into a smaller airway, thus occluding the airway. ${ }^{8,10}$ Furthermore, cut tubing could have a sharp tip that could perforate or damage bronchial tissue. $^{7}$

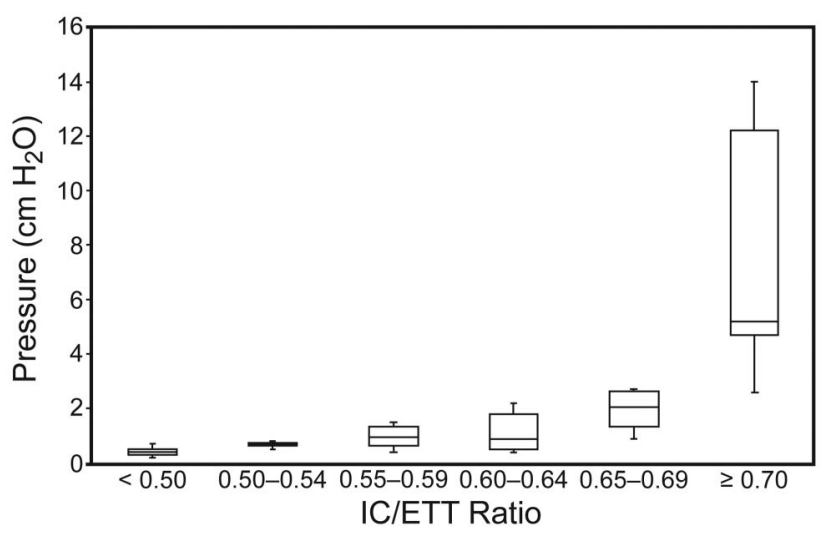

Fig. 1. Pressures generated in the test lung, during the apnea test, with 6 ratios of outer diameter of insufflation catheter (IC) to inner diameter of endotracheal tube (ETT), with an oxygen flow of $6 \mathrm{~L}$ min. In each data the horizontal line represents the median, the bottom and top of the bar represent the 25th and 75th percentiles, and the whiskers represent the range.

IC/ETT ratios $>0.89$ caused the test lung to continue inflating without reaching a plateau. If the test lung fully inflated (peak pressure $>22 \mathrm{~cm} \mathrm{H}_{2} \mathrm{O}$ and volume $>1,100 \mathrm{~mL}$ ) we disconnected the test lung from the manikin, to prevent damage to the test lung, and therefore did not obtain sustained end-point pressures and volumes for IC/ETT ratios $>0.89$.

At $6 \mathrm{~L} / \mathrm{min}$ there were statistically significant differences between the mean pressures and volumes for IC/ ETT ratios $\geq 0.7$, so our null hypothesis was rejected. We therefore recommend that in the apnea test the outer diameter of the IC should not exceed $70 \%$ of the inner diameter of the ETT. For instance, we recommend an IC of $\leq 12$ French when performing the apnea test through a $6.5 \mathrm{~mm}$ inner diameter ETT, $\leq 14$ French in a $7.5 \mathrm{~mm}$

Table 2. Measured Peak Pressures in the Test Lung During the Apnea Test

\begin{tabular}{|c|c|c|c|c|c|c|c|c|c|c|}
\hline & \multicolumn{10}{|c|}{ Peak Pressure, mean $\pm \mathrm{SD} \mathrm{cm} \mathrm{H}_{2} \mathrm{O}$} \\
\hline & $6 \mathrm{~L} / \mathrm{min}$ & $7 \mathrm{~L} / \mathrm{min}$ & $8 \mathrm{~L} / \mathrm{min}$ & $9 \mathrm{~L} / \mathrm{min}$ & $10 \mathrm{~L} / \mathrm{min}$ & $11 \mathrm{~L} / \mathrm{min}$ & $12 \mathrm{~L} / \mathrm{min}$ & $13 \mathrm{~L} / \mathrm{min}$ & $14 \mathrm{~L} / \mathrm{min}$ & $15 \mathrm{~L} / \mathrm{min}$ \\
\hline \multicolumn{11}{|c|}{ IC/ETT ratio } \\
\hline $\begin{array}{l}<0.5 \\
\quad(n=9)\end{array}$ & $0.41 \pm 0.19$ & $0.56 \pm 0.30$ & $0.80 \pm 0.31$ & $0.90 \pm 0.38$ & $1.09 \pm 0.43$ & $1.37 \pm 0.64$ & $1.58 \pm 0.66$ & $1.73 \pm 0.65$ & $2.11 \pm 0.85$ & $2.52 \pm 1.51$ \\
\hline $\begin{array}{l}0.5-0.54 \\
\quad(n=4)\end{array}$ & $0.68 \pm 0.13$ & $1.23 \pm 0.60$ & $1.48 \pm 0.48$ & $1.75 \pm 0.57$ & $2.08 \pm 0.64$ & $2.33 \pm 0.55$ & $2.70 \pm 0.67$ & $3.23 \pm 0.78$ & $3.63 \pm 1.34$ & $3.83 \pm 1.31$ \\
\hline $\begin{array}{r}0.55-0.59 \\
\quad(n=6)\end{array}$ & $0.97 \pm 0.44$ & $1.25 \pm 0.64$ & $1.60 \pm 0.81$ & $2.12 \pm 1.37$ & $2.25 \pm 1.23$ & $2.77 \pm 1.67$ & $3.17 \pm 1.72$ & $4.13 \pm 2.94$ & $4.28 \pm 2.81$ & $4.9 \pm 3.19$ \\
\hline $\begin{array}{l}0.6-0.64 \\
\quad(n=5)\end{array}$ & $1.16 \pm 0.80$ & $1.48 \pm 1.11$ & $1.82 \pm 1.24$ & $2.22 \pm 1.58$ & $2.62 \pm 1.65$ & $3.02 \pm 2.16$ & $3.38 \pm 2.28$ & $3.78 \pm 2.72$ & $4.34 \pm 3.09$ & $4.68 \pm 3.24$ \\
\hline $\begin{array}{r}0.65-0.69 \\
(n=4)\end{array}$ & $1.93 \pm 0.87$ & $2.28 \pm 1.06$ & $3.13 \pm 1.66$ & $4.0 \pm 2.50$ & $4.88 \pm 2.93$ & $5.95 \pm 4.08$ & $5.38 \pm 2.51$ & $7.48 \pm 5.31$ & $8.63 \pm 5.88$ & $8.53 \pm 5.13$ \\
\hline$\geq 0.7$ & $\begin{array}{c}6.73 \pm 4.72 \\
(n=10)\end{array}$ & $\begin{array}{c}8.48 \pm 6.06 \\
\quad(n=10)\end{array}$ & $\begin{array}{c}9.16 \pm 5.68 \\
\quad(n=10)\end{array}$ & $\begin{array}{c}11.18 \pm 7.35 \\
(n=9)\end{array}$ & $\begin{aligned} 9.57 & \pm 5.60 \\
(n & =7)\end{aligned}$ & $\begin{array}{c}8.78 \pm 3.72 \\
\quad(n=6)\end{array}$ & $\begin{array}{c}9.7 \pm 4.19 \\
(n=6)\end{array}$ & $\begin{array}{c}11.23 \pm 4.89 \\
(n=6)\end{array}$ & $\begin{array}{c}12.65 \pm 5.64 \\
(n=6)\end{array}$ & $\begin{array}{c}14.03 \pm 5.67 \\
\quad(n=6)\end{array}$ \\
\hline
\end{tabular}

IC/ETT ratio $=$ ratio of the outer diameter of the insufflation catheter to the inner diameter of the endotracheal tube 
Apnea Testing: The Effects of Insufflation Catheter Size and Flow

Table 3. Measured Peak Volumes in the Test Lung During the Apnea Test

\begin{tabular}{|c|c|c|c|c|c|c|c|c|c|c|}
\hline & \multicolumn{10}{|c|}{ Peak Volume, mean $\pm \mathrm{SD} \mathrm{mL}$} \\
\hline & $6 \mathrm{~L} / \mathrm{min}$ & $7 \mathrm{~L} / \mathrm{min}$ & $8 \mathrm{~L} / \mathrm{min}$ & $9 \mathrm{~L} / \mathrm{min}$ & $10 \mathrm{~L} / \mathrm{min}$ & $11 \mathrm{~L} / \mathrm{min}$ & $12 \mathrm{~L} / \mathrm{min}$ & $13 \mathrm{~L} / \mathrm{min}$ & $14 \mathrm{~L} / \mathrm{min}$ & $15 \mathrm{~L} / \mathrm{min}$ \\
\hline \multicolumn{11}{|l|}{ IC/ETT ratio } \\
\hline $\begin{array}{l}<0.5 \\
\quad(n=9)\end{array}$ & $21.11 \pm 9.49$ & $30.89 \pm 14.35$ & $40.44 \pm 16.15$ & $46 \pm 18.79$ & $52 \pm 26.66$ & $69.89 \pm 31.87$ & $82.44 \pm 31.5$ & $91.33 \pm 32.65$ & $109.78 \pm 43.03$ & $126.11 \pm 75.65$ \\
\hline $\begin{array}{c}0.5-0.54 \\
(n=4)\end{array}$ & $35.25 \pm 5.74$ & $62 \pm 30.40$ & $75 \pm 26.38$ & $89.25 \pm 27.54$ & $105 \pm 34.27$ & $117.5 \pm 28.07$ & $138.25 \pm 31.81$ & $165 \pm 39.15$ & $185.25 \pm 67.18$ & $193 \pm 65.31$ \\
\hline $\begin{array}{c}0.55-0.59 \\
(n=6)\end{array}$ & $49.67 \pm 22.12$ & $64.33 \pm 31.83$ & $80.67 \pm 40.27$ & $106.17 \pm 67.94$ & $114 \pm 61.64$ & $141.17 \pm 83.49$ & $164.33 \pm 86.34$ & $211.17 \pm 147.59$ & $218 \pm 137.57$ & $245.17 \pm 159.16$ \\
\hline $\begin{array}{c}0.6-0.64 \\
\quad(n=5)\end{array}$ & $58.6 \pm 39.48$ & $77 \pm 55.73$ & $91.8 \pm 60.43$ & $111.8 \pm 78.64$ & $132.8 \pm 83.39$ & $153.2 \pm 107.81$ & $171.8 \pm 112.86$ & $195.2 \pm 137.32$ & $223.2 \pm 154.39$ & $235.2 \pm 161.62$ \\
\hline $\begin{array}{r}0.65-0.69 \\
(n=4)\end{array}$ & $98.25 \pm 44.06$ & $115.5 \pm 51.72$ & $157.5 \pm 82.28$ & $201.5 \pm 123.10$ & $245.25 \pm 147.56$ & $298 \pm 206.19$ & $271.25 \pm 122.22$ & $378.25 \pm 267.38$ & $437.5 \pm 294.05$ & $428.25 \pm 259.82$ \\
\hline$\geq 0.7$ & $\begin{aligned} 337.4 & \pm 237.51 \\
(n & =10)\end{aligned}$ & $\begin{array}{c}427.1 \pm 302.91 \\
\quad(n=10)\end{array}$ & $\begin{aligned} 458.6 & \pm 283.49 \\
n & =10)\end{aligned}$ & $\begin{aligned} 561.33 & \pm 367.92 \\
(n & =9)\end{aligned}$ & $\begin{aligned} 481.29 & \pm 280.25 \\
(n & =7)\end{aligned}$ & $\begin{aligned} 490 & \pm 194.41 \\
(n & =6)\end{aligned}$ & $\begin{aligned} 489.5 & \pm 210.25 \\
(n & =6)\end{aligned}$ & $\begin{aligned} 566.67 & \pm 245.79 \\
(n & =6)\end{aligned}$ & $\begin{aligned} 587.67 & \pm 233.86 \\
(n & =6)\end{aligned}$ & $\begin{array}{c}701.83 \pm 283.59 \\
n=6)\end{array}$ \\
\hline
\end{tabular}

IC/ETT ratio $=$ ratio of the outer diameter of the insufflation catheter to the inner diameter of the endotracheal tube

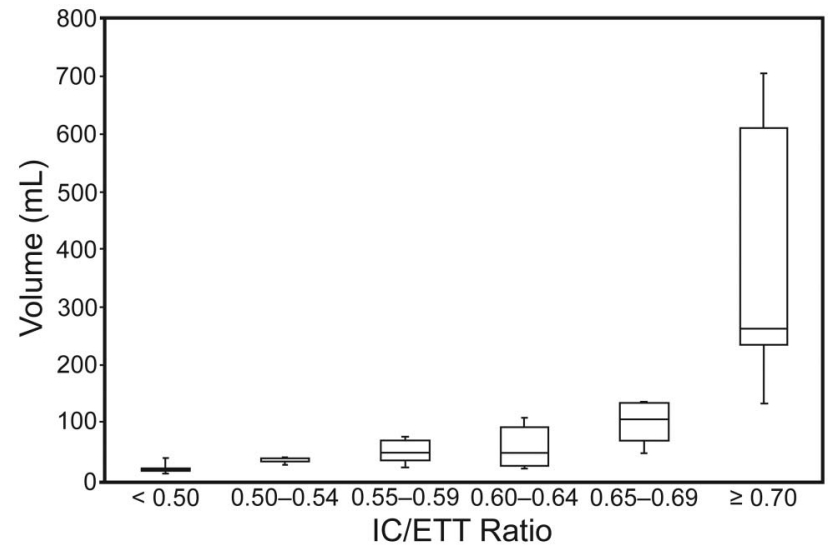

Fig. 2. Volumes generated in the test lung, during the apnea test, with 6 ratios of outer diameter of insufflation catheter (IC) to inner diameter of endotracheal tube (ETT), with an oxygen flow of $6 \mathrm{~L} /$ min. In each data the horizontal line represents the median, the bottom and top of the bar represent the 25th and 75th percentiles, and the whisker bars represent the range.

inner diameter ETT, and $\leq 16$ French in a $8.0 \mathrm{~mm}$ inner diameter ETT.

Increasing the oxygen flow above the American Academy of Neurology recommend $6 \mathrm{~L} / \mathrm{min}$ increased the pressures and volumes in the test lung, which could cause complications. As seen in Tables 2 and 3, the pressures and volumes were minimized at $6 \mathrm{~L} / \mathrm{min}$. We therefore conclude that $6 \mathrm{~L} / \mathrm{min}$ is the appropriate flow during the apnea test.

Our results differ from those of Olguner et al, who used a 2.3-L anesthesia bag as a lung model ${ }^{14}$ and performed the apnea test with ETTs of 7.0 to $8.0 \mathrm{~mm}$ inner diameter, ICs of 8 to 14 French, and flows of 6,8 , and $10 \mathrm{~L} / \mathrm{min} .{ }^{14}$ Olguner et al calculated the IC/ETT ratio by dividing the ETT inner diameter by the IC outer diameter, ${ }^{14}$ which is the inverse of the traditional ratio calculation. ${ }^{11-13}$ Olguner concluded that ETT/IC ratio of $<1.75$ was significantly different and associated with higher pressure in their lung model than diameter-based ETT/IC ratios $>1.75 .{ }^{14} \mathrm{We}$ converted our IC/ETT ratios to ETT/IC ratios to compare our findings to those of Olguner et al.

Our findings may differ from Olguner's study for several reasons. First, Olguner used an anesthesia bag as a lung model, and the compliance of the anesthesia bag was not determined. Second, Olguner used a pressure transducer that was calibrated for air, but then used $100 \%$ oxygen in the tests. Third, Olguner tested only 3 ETT sizes, whereas we tested 9 ETT sizes. ${ }^{14}$

Our data suggest that as the IC/ETT ratio increases, the pressures and volumes also increase. Lang and Heckmann stated that barotrauma may be prevented during the apnea test by limiting the oxygen flow, using an appropriate IC/ETT ratio, and not advancing the IC past the ETT tip. ${ }^{9}$ Our study supports that statement, and we further recommend an IC/ETT ratio of $<70 \%$, to prevent excessive pressure and volume during the apnea test.

\section{Limitations}

We tested clean ETTs, whereas, in a patient, dried secretions can decrease the ETT inner diameter, so when choosing an IC size the clinician should consider a smaller IC if the patient has thick or tenacious secretions.

The test lung we used had a maximum volume of $1,200 \mathrm{~mL}$, so we could not test IC/ETT ratios $>0.89$, and the test lung had pre-set compliance. Lung compliance differences between patients, and lung compliance variation within an individual patient, would affect the pressures and volumes generated in the lungs.

We studied only adult-size ETTs. The apnea test is also performed in pediatric patients, with ETTs of $3.0-5.5 \mathrm{~mm}$ inner diameter. 


\section{Apnea Testing: The Effects of Insufflation Catheter Size and Flow}

\section{Conclusions}

The IC/ETT ratio should not exceed $70 \%$. This finding, coupled with the current American Academy of Neurology guidelines for the determination of brain death, may improve pulmonary outcomes and reduce the risk of procedure-related complications.

\section{ACKNOWLEDGMENTS}

We thank Christopher Russian MEd RRT-NPS RPSGT and Joshua Gonzales MHA RRT-NPS SDS for their contributions in developing the research idea, and Lynda Harkins PhD RRT for assistance with statistical analysis

\section{REFERENCES}

1. Wijdicks, EFM, Varelas PN, Gronseth GS, Greer DM. Evidencebased guideline update: determining brain death in adults. Neurology 2010;74(23):1911-1918. DOI: 10.1212/WNL.0b013e3181e242a8.

2. Report of the quality standards subcommittee of the American Academy of Neurology. Practice parameters for determining brain death in adults: summary statement. Neurology 1995;45(5):1012-1014.

3. Saposnik G, Rizzo G, Deluca JL. Pneumothorax and pneumoperitoneum during the apnea test: how safe is this procedure? Arq Neuropisquiatr 2000;58(3-B):905-908.

4. Saposnik G, Rizzo G, Vega A, Sabbatiello R, Deluca JL. Problems associated with the apnea test in the diagnosis of brain death. Neurol India 2004;52(3):342-345.
5. Xiao-liang WU, Qiang FANG, Li Li, Yun-qing QIU, Ben-yan LUO. Complications associated with the apnea test in the determination of brain death. Chin Med J 2008;121(13):1169-1172.

6. Machado C, Perez J, Scherle C, Areu A, Pando A. Brain death diagnosis and apnea test safety. Ann Indian Acad Neurol 2009;12(3): 197-200. DOI: 10.4103/0972-2327.56326.

7. Burns JD, Russell JA. Tension Pneumothorax complicating apnea testing during brain death evaluation. J Clin Neurosci 2008;15(5): 580-582. DOI: 10.1016/j.jocn.2007.02.009.

8. Monterrubio-Villar J, Cordabo-Lopez A. Barotrauma during apnoea testing for brain death determination in a five-year-old boy. Anesth Intensive Care 2008;36(3):462-463.

9. Lang CJG, Heckmann JG. Apnea testing for the diagnosis of brain death. Acta Neurol Scand 2005;112(6):358-369.

10. Bar-Joseph G, Bar-Lavie Y, Zonis Z. Tension pneumothorax during apnea testing for the determination of brain death. Anesthesiology 1998;89(5):1250-1251.

11. Restrepo R, Brown J, Hughes J. AARC clinical practice guideline: endotracheal suctioning of mechanically ventilated patients with artificial airways 2010. Respir Care 2010;55(6):758-764.

12. Rossen M, Hillard E. The effects of negative pressure during tracheal suction. Anesth Analg 1962;41(1):50-57.

13. Tiffin NH, Keim MR, Frewen TC. The effects of variations in flow through an insufflating catheter and endotracheal-tube and suction-catheter on test-lung pressures. Respir Care 1990;35(9):889897.

14. Olguner C, Koca U, Akan M, Karci A, Elar Z. The safe limits of mechanical factors in the apnea testing for the diagnosis of brain death. Tohoku J Exp Med 2007;211(2):115-120. 